\title{
Obesity in Relationship with Different Forms of Myocardial Infarction (Data of Registry on Acute Myocardial Infarction)
}

\author{
Anvarovna NG* \\ Republican Specialized Scientific and Practical Medical Center of Cardiology, Ministry of Health of the Republic of \\ Uzbekistan, Tashkent, Uzbekistan
}

"Correspondence: Nagaeva Gulnora Anvarovna, Republican Specialized Scientific and Practical Medical Center of Cardiology, Ministry of Health of the Republic of Uzbekistan, Tashkent, Uzbekistan

Received on 29 May 2020; Accepted on 02 July 2020; Published on 10 July 2020

Copyright () 2020 Anvarovna NG. This is an open access article and is distributed under the Creative Commons Attribution License, which permits unrestricted use, distribution, and reproduction in any medium, provided the original work is properly cited.

\begin{abstract}
In today's world, the growth of technical progress has increased the number of people with obesity, which is one of the main risk factors for the development of acute myocardial infarction $(M I)$.

Objective: To evaluate the effect of obesity on some clinical and anthropometric characteristics in patients with acute MI.

Material and Methods: A special questionnaire - a "registry card" was developed for monitoring patients with acute MI and collecting the necessary and complete information from employees of the Cardiovascular Diseases (CVD) Prevention Department. The presented article describes the data of a preliminary analysis of patients with acute MI treated in the clinic. Of the 202 people, 191 (94.6\%) had a body mass index (BMI) calculated. Depending on the level of BMI, three groups were selected: $1 \mathrm{~g}\left(B M I<25 \mathrm{~kg} / \mathrm{m}^{2}\right)-36$ (18.8\% of 191) patients with acute MI with normal weight (control group); $2 \mathrm{~g}\left(B M I=25-30 \mathrm{~kg} / \mathrm{m}^{2}\right)-84(44.0 \%$ of 191$)$ overweight people; $3 \mathrm{~g}\left(\mathrm{BMI}>30 \mathrm{~kg} / \mathrm{m}^{2}\right)-71(37.2 \%$ of 191) people with obesity. Differences were considered significant at $p<0.05$.

Results: Despite the fact that acute MI developed in women 2.6 times less frequently and 8.7 years later in age than in men, nevertheless, obesity in women was recorded more often, while in men overweight prevailed. In acute MI between the age of the respondents and the presence of increased weight, an inverse relationship was revealed ( $p>0.05$ ), i.e., as the weight category increased, the age of the patients decreased. In patients with MI, as the weight increased, there was an increase in comorbid pathology, especially associated with impaired carbohydrate metabolism ( $p<0.0001)$. A more severe form of MI (STEMI) was more often recorded in persons with a BMI $>25 \mathrm{~kg} / \mathrm{m}^{2}$, while the front wall was the most vulnerable to the development of acute MI, regardless of the weight category of patients. The back wall was involved in the pathological process both in individuals with overweight and in patients with obesity. The apical segment in the largest number of cases was only affected in people with obesity.

Conclusion: Obesity is a kind of epidemic of modern society. Its effects on the quality of life,
\end{abstract}


prognosis, and effectiveness of conservative or minimally invasive treatment methods in patients with acute cardiovascular catastrophes, such as acute MI, are still a very controversial issue that requires furthermore in-depth study and analysis.

Keywords: obesity, acute myocardial infarction, age, gender, localization of acute myocardial infarction

Abbreviations: MI: myocardial infarction; CVD: cardiovascular diseases; BMI: body mass index; RSSPMCC: Republican specialized scientific-practical medical center of cardiology; STEMI: ST-elevation myocardial infarction; NSTEMI: Non-ST-elevation myocardial infarction; ECG: electrocardiogram; AH: arterial hypertension; LW: lateral wall of the left ventricle

\section{Introduction}

Obesity is currently an epidemic in many countries, which has become one of the major problems of world health, as it is associated with a high level of cardiovascular morbidity [1]. In the world, the prevalence of obesity increased more than 2 times between 1980 and 2014 [2]. Obesity is also seen as a risk factor for high mortality in the general population. The lowest mortality rate is observed with a body mass index (BMI) in the range of $20-24.9 \mathrm{~kg} / \mathrm{m}^{2}$ (nonsmokers in American and European populations) and increases below and above this range [3, 4].

In the hospital period of acute myocardial infarction (MI), all patients are at high risk. Therefore, the search continues for methods to improve the prognosis for this category of patients, the identification of patients with an unfavorable course of the disease, as well as the individualization of therapeutic approaches [5].

However, it should be emphasized that in most works devoted to the problem of acute MI, they approach the study of the issue from the standpoint of the "average patient", without taking into account the individual characteristics of its somatic structure. At the same time, many studies have proved the reasonable need for a constitutional approach in medicine [5-8]. In cardiology, the use of constitutional division to assess various aspects of the etiology, clinical course of acute MI occurs in individual publications [9-12].

The purpose of this fragment of the study was to evaluate the effect of obesity on some clinical and anthropometric characteristics in patients with acute MI.

\section{Materials and Methods}

For monitoring patients with acute MI and collecting necessary and complete information, the staff of the Department of Prevention of Cardiovascular Diseases (CVD) Center developed a special questionnaire (card-register), which includes the main parameters of the condition of the clinic of Republican Specialized Scientific-Practical Medical Center of Cardiology (RSSPMCC), laboratory and functional characteristics, specific scales and treatment.

The volume of the card-register occupies full 3 sheets of A4 format. The main emphasis in gathering information and filling the card-register was made on the vastness/depth [ST-elevation myocardial infarction (STEMI) or Non-STelevation myocardial infarction (NSTEMI)] and localization (which walls of the left ventricle-LW) cardiac damage, the presence of various risk factors and associated pathological conditions.

The card-register was used in two versions - paper and electronic (as an Excel database). The electronic version was a copy of a paper version with similar questions.

The presented article describes a preliminary analysis of the database of personal data of 202 patients treated in the clinic of RSSPMCC with a diagnosis of acute MI for 2018.

The analysis of the data of all patients with MI during the register assumed the following conditions to be met: 
- Patients must meet inclusion criteria.

- Patient involvement should not influence the approaches to his treatment.

- The inclusion of the patient in the register must be accompanied by his registration in the register database.

\section{Inclusion criteria}

The register included patients aged from 18-75 years hospitalized with acute MI in the relevant hospitals. Acute MI was diagnosed based on generally accepted criteria:

- Typical pain syndrome.

- The appearance of a new Q wave on the electrocardiogram (ECG).

- The dynamics of the ST segment and the T wave on the ECG.

- Dynamics of myocardial damage markers (as tests are performed).

\section{Exclusion criteria}

- $\quad$ Age under 18 and over 75 years.

This study was a pilot, prospectin and covered the collection of information according to the "map-register" questionnaire for all patients diagnosed with acute MI treated for one (2018) calendar year in our clinic.

\section{Statistical analysis of the results}

Statistical processing of the results was carried out on a Pentium-IV personal computer using the STATISTICA 6 software package. Calculate the arithmetic mean (M) and root-mean-square standard deviation (SD). To avoid statistical inaccuracy, the analysis was accompanied by checking the normal distribution of clinical signs. To compare the arithmetic means of the two groups, the Student's t-test was used. To assess the presence of relationships between indicators, a correlation analysis was performed with the calculation of the Pearson correlation coefficient. To analyze the reliability of differences between qualitative signs, the $\chi^{2}$ criterion was used. In cases where the number of data in the compared groups was less than 30 and at least one group was less than 5, the results were checked using the exact Fisher method.

All values are presented as arithmetic mean \pm standard deviation $(M \pm S D)$. Differences were considered significant at $\mathrm{p}<0.05$.

\section{Results}

This article describes the data of a preliminary analysis of patients with acute MI. Of the 202 people, 191 (94.6\%) had BMI calculated. Depending on the level of BMI, three groups were distinguished: $1 \mathrm{~g}$ - 36 (18.8\% of 191) acute MI patients with normal weight (control group), BMI $<25 \mathrm{~kg} / \mathrm{m}^{2} ; 2 \mathrm{~g}-84$ (44.0\% of 191) overweight people, BMI $=25-$ $30 \mathrm{~kg} / \mathrm{m}^{2}$ and $3 \mathrm{~g}-71$ (37.2\% of 191) people with obesity of varying severity, BMI $>30 \mathrm{~kg} / \mathrm{m}^{2}$ (Table 1 ).

In all three groups, males prevailed: 138/53 (male/female). The average age of the respondents in the group as a whole was $60.24 \pm 10.01(27-80)$ years. The average age of men was $57.83 \pm 9.61$ years, and for women was $66.53 \pm 8.19$ years $(\mathrm{p}<0.0001)$. The number of persons with normal weight in the male population were 26 (18.8\% of 138), with overweight were 64 (46.4\% of 138) and with obesity were 48 (34.8\% of 138) people. Among women, similar figures were 10, 20 and $23(18.9 \%, 37.7 \%$ and $43.4 \%$ of 53), respectively (Table 1). As can be seen from the presented data among men, the largest number was in overweight patients, on the contrary, among women, the greatest number was in patients with obesity (all $\mathrm{p}>0.05$ ). That is, in spite of the fact that acute MI developed in women 2.6 times less frequently and 8.7 years later in age than in men, however, obesity in women was recorded more frequently, while in men prevailed overweight. 


\begin{tabular}{|l|l|l|l|}
\hline Sign & 1st group (control) & 2nd group & 3rd group \\
\hline Number of patients & $\mathrm{n}=36$ & $\mathrm{n}=84$ & $\mathrm{n}=71$ \\
\hline Age (years) & $62.3 \pm 9.4$ & $60.3 \pm 10.4$ & $59.2 \pm 9.8$ \\
\hline Men, $\mathrm{n}(\%)$ & $26(72.2 \%)$ & $64(76.2 \%)$ & $48(67.6 \%)$ \\
\hline Women, $\mathrm{n}(\%)$ & $10(27.8 \%)$ & $20(23.8 \%)$ & $23(32.4 \%)$ \\
\hline Height $(\mathrm{cm})$ & $167.06 \pm 5.57$ & $169.07 \pm 7.84$ & $167.31 \pm 8.28$ \\
\hline Weight $(\mathrm{kg})$ & $65.42 \pm 6.65$ & $78.93 \pm 8.15^{* *}$ & $95.55 \pm 11.73$ \\
\hline BMI $\left(\mathrm{kg} / \mathrm{m}^{2}\right)$ & $23.39 \pm 1.47$ & $27.56 \pm 1.47^{* *}$ & $34.11 \pm 3.23^{* *}$ \\
\hline Obesity grade $1, \mathrm{n}(\%)$ & - & - & $44(62.0 \%$ of 71$)$ \\
\hline Obesity grade 2, $\mathrm{n}(\%)$ & - & - & $23(32.4 \%$ of 71$)$ \\
\hline Obesity grade 3, $\mathrm{n}(\%)$ & - & - & $4(5.6 \%$ of 71$)$ \\
\hline Mean grade of obesity & - & - & $1.44 \pm 0.60$ \\
\hline TMI history & $5(13.9 \%)$ & $11(13.1 \%)$ & $10(14.1 \%)$ \\
\hline D & $3(8.33 \%)$ & $24(28.6 \%)^{*}$ & $23(32.4 \%)^{*}$ \\
\hline AH & $28(77.8 \%)$ & $68(81.0 \%)$ & $65(91.5 \%)$ \\
\hline
\end{tabular}

Table 1: Anthropometric characteristics of the compared patient groups. Notes $\mathrm{n}$ : the number of patients; BMI: body mass index; TMI: transferred myocardial infarction; D: diabetes mellitus; AH: arterial hypertension; * and **: significance of differences at $\mathrm{p}<0.05$ and $\mathrm{p}<0.001$ in comparison with the data of group 1 (control group).

When conducting a correlation analysis between the age of the respondents and the presence of increased weight, an inverse relationship was found, which, however, did not reach the level of confidence (Figure 1), that is, as the weight category increased, the age of the patients decreased and obesity occurred in younger respondents (Table 1).

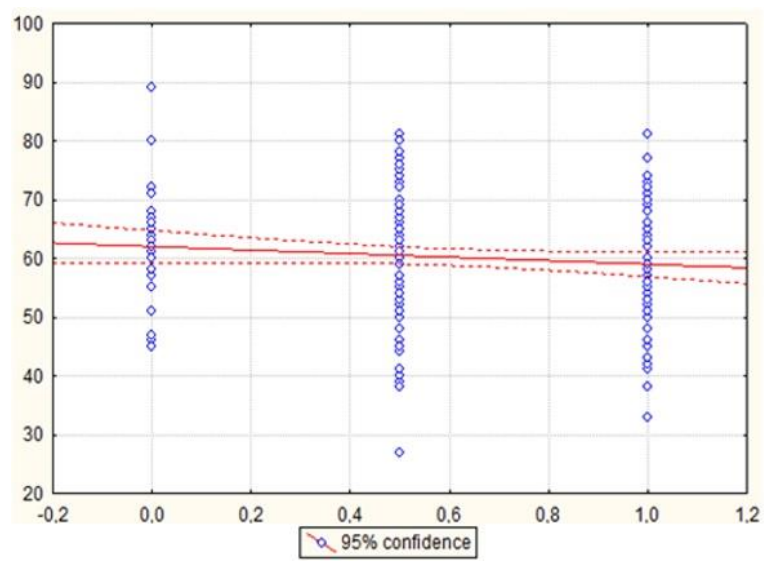

Figure 1: Graph of correlation between age respondents and the presence of obesity. $\mathrm{p}=0.131 ; \mathrm{r}=-0.109 ; \mathrm{t}=-1.513$. Notes: On the $\mathrm{X}$ axis, under the number " 0 ": patients with normal weight; under the number " 0.5 ": patients with overweight and under the number "1": patients with obesity. On the Y-axis: age of patients.

Assessment of concomitant comorbid conditions found that arterial hypertension (AH) was more than $75 \%$ of respondents, while as the weight of patients increased, an increase in the number of people with AH was observed (77.8\% in patients from $1 \mathrm{~g}$ group to $81.0 \%$ in patients from $2 \mathrm{~g}$ group and up to $91.5 \%$ in patients from $3 \mathrm{~g}$ group, both $\mathrm{p}>0.05$ ) and in the greatest number of cases the $\mathrm{AH}$ was recorded in people with obesity (Table 1). Disorders of carbohydrate metabolism were characterized by a pronounced dependence with weight gain. Namely, in patients of $2 \mathrm{~g}$ group, the number of patients with the presence of type 2 diabetes turned out to be 8 times greater than that of respondents with normal weight. A similar trend was observed in patients of group 3 (both $p<0.05$ ). Thus, in patients with acute MI, as the weight increased, an increase in comorbid pathology, especially associated with impaired carbohydrate metabolism, was observed.

This was confirmed by a correlation analysis between the degree of obesity and the total component of risk factors (Figure 2). Risk factors included obesity, smoking, decreased CKD-EPI $<60 \mathrm{ml} / \mathrm{min} / 1.73 \mathrm{~m}^{2}$, type 2 diabetes mellitus, hypertension, and a decrease in the ejection fraction of the left ventricular $<55 \%$. The average level of the total component in the group as a whole was $2.6 \pm 1.1$, but directly in patients with obesity was $3.3 \pm 0.9$. 


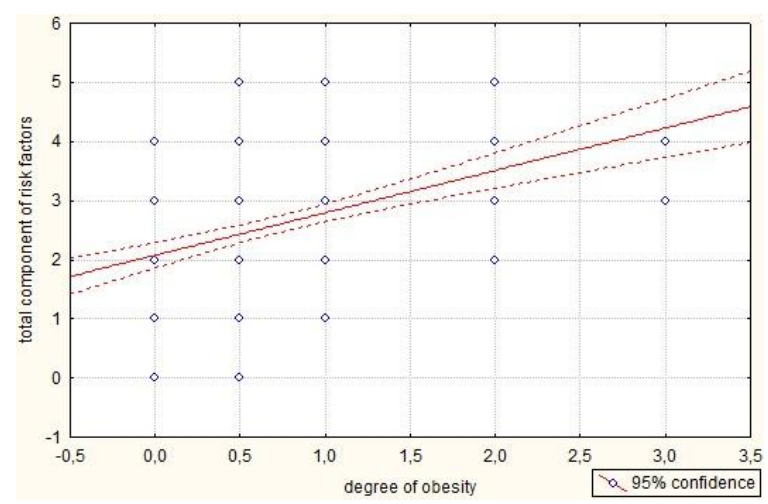

Figure 2: A graph of the correlation between the degree of obesity and the total component of risk factors. $p=0.000 ; r=0.433 ; t=6.611$. Notes: Along the $\mathrm{X}$ axis, under the number " 0 ": patients with normal weight; under the number " 0.5 ": patients with overweight; under the number " 1 ": patients with the presence of obesity of the I degree; under the number "2": patients with the presence of obesity II degree; under the number "3": patients with the presence of obesity of the III degree. Along the Y axis: the sum of the estimated risk factors.

Of the 191 patients examined, 115 (60.2\%) were diagnosed with STEMI and 76 (39.8\%) with NSTEMI. Evaluation of the incidence of various forms of MI in the analyzed groups found that STEMI was more often observed among individuals of the 2nd and 3rd groups, i.e., with a BMI $>25 \mathrm{~kg} / \mathrm{m}^{2}$. In contrast, NSTEMI was more common in people with normal weight (Figure 3). From the foregoing it follows that a more severe form of MI (STEMI) was more often recorded in persons whose BMI exceeds normal values.

A more in-depth analysis of the compared groups of patients, depending on the location of the lesions, established that (Figure 3), for people with normal weight, MI was most often recorded on the anterior (61.1\%) and lateral (27.8\%) walls. Patients in 2nd group (overweight) were characterized by lesions of the anterior (39.3\%) and posterior (38.1\%) left ventricle walls. In the 3rd group (with obesity), MI was more often recorded on the anterior (43.7\%), posterior (25.4\%) walls and apical (21.1\%) segments. Circular MI in all three groups was very rare $(2.8 \%, 3.6 \%$ and $2.8 \%$, respectively in the 1 st, 2 nd, and 3rd groups).

Thus, from the above, we can conclude that the anterior wall was the most vulnerable to the development of MI, regardless of the weight category of patients; the back wall was involved in the pathological process both in individuals with overweight and in patients with obesity; the apical segment in the greatest number of cases was only affected in people with obesity (Figure 4).

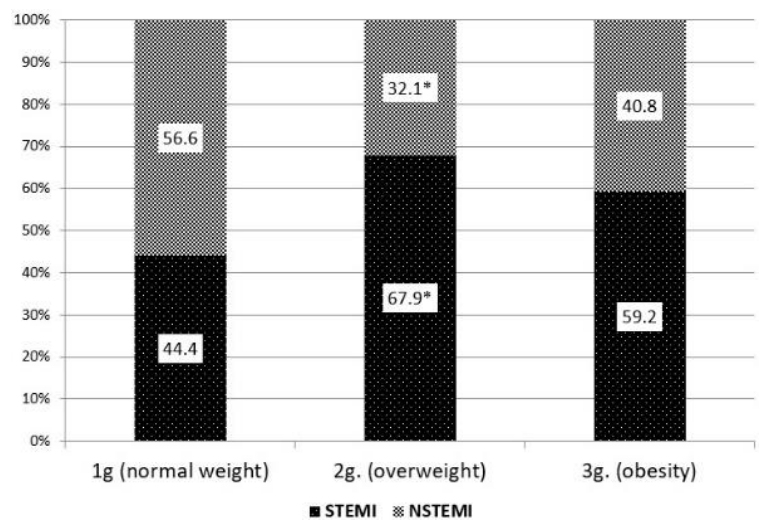

Figure 3: Occurrence of various forms of acute MI depending from the weight category of patients. Note: Data are presented in percentage; *: reliability differences at $\mathrm{p}<0.05$ when compared with the data of the control group. 


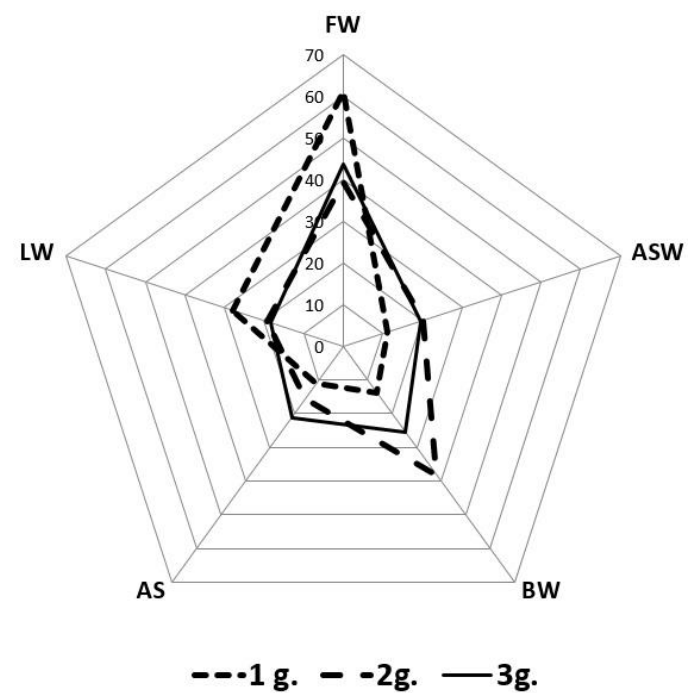

Figure 4: Localization of lesions in MI, depending from the weight category of patients. Notes: Data are presented in percentage; FW: front wall; ASW: anterior septum wall; BW: back wall; AS: apical segment; LW: lateral wall.

\section{Discussion}

CVD continue to occupy a leading position among the causes of death in industrialized countries. Among them, the leading role is played by MI, which is known to be more common in men than in women [13]. At the same time, in recent years there has been an increase in the incidence of MI in women [14, 15]. Among all risk factors, obesity occupies a special place, the prevalence of which in women is known to be higher than in men. According to the literature, patients with obesity and acute MI are usually younger [11]. A similar pattern was observed in our study.

With age, as the deterioration of metabolic processes takes place, there is an increase in comorbidity. Most often, coronary heart disease is combined with hypertension and type 2 diabetes. The presence of hypertension in diabetes increases the risk of not only macrovascular (coronary artery disease, heart failure, stroke), but also microvascular (diabetic nephropathy, retinopathy) complications. The lesion of coronary, cerebral and peripheral vessels is the basis of macrovascular complications in type 2 diabetes and largely determines the prognosis of the disease. AH significantly increases the already increased risk of morbidity and mortality in patients with diabetes. In patients with hypertension and type 2 diabetes, overall mortality is 4-7 times higher than in patients with normal blood pressure and without diabetes $[16,17]$. According to the literature, hypertension can be a consequence, so, perhaps, the cause of the development of type 2 diabetes $[18,19]$. In our registry, patients with normal weight were characterized by the presence of hypertension in over $75 \%$ of cases, and among patients with a BMI $>25 \mathrm{~kg} / \mathrm{m}^{2}$, the presence of hypertension was recorded in more than $80 \%$ of patients. Also, in our study, it was found that the presence of type 2 diabetes increased dramatically ( 8 times) in patients with a BMI $>25 \mathrm{~kg} / \mathrm{m}^{2}$.

In the recommendations of the European Society of Cardiology for the Prevention of Cardiovascular Diseases in clinical practice, it is emphasized that obesity among the population leads to an increase in cardiovascular morbidity and mortality. The recommendation for weight loss in overweight or obese people for primary prevention of cardiovascular events is Class I, Level A, since weight loss to normal (BMI 20-24.9 $\mathrm{kg} / \mathrm{m}^{2}$ ) has a positive effect on blood pressure, plasma lipids, and a decrease in cardiovascular morbidity [20]. Interestingly, so far, no studies have confirmed the reduction in mortality after MI in patients who have reduced their body weight [21]. At the same time, it is a well-known fact that in the case of already established cardiovascular diseases, mortality in patients with overweight and obesity is often lower than in people with normal body weight. This phenomenon is known as the "obesity paradox", the exact mechanism of which is not yet clear [22].

Contradictory information about the effect of obesity on the risk of acute MI and its particular course requires research with qualitative randomization of patients by age, comorbidities, the specific features of therapy and, of course, the method of evaluating obesity. It can be assumed that the issue of the "obesity paradox", including in acute MI, will be 
exhausted if the parameters of visceral obesity, which naturally and unambiguously have a negative effect on cardiovascular risk, will be taken into account to a large extent without obvious paradoxes $[4,23,24]$.

\section{Conclusion}

- Despite the fact that acute MI developed in women 2.6 times less frequently and 8.7 years later in age than in men, nevertheless, obesity in women was recorded more often, while in men, overweight prevailed.

- In acute MI between the age of respondents and the presence of increased weight, an inverse relationship was revealed ( $p>0.05)$, i.e., as the weight category increased, the age of the patients decreased.

- In patients with acute MI, as the weight increased, there was an increase in comorbid pathology, especially associated with impaired carbohydrate metabolism $(\mathrm{p}<0.0001)$.

- A more severe form of acute MI (STEMI) was more often recorded in persons with BMI $>25 \mathrm{~kg} / \mathrm{m}^{2}$, while the front wall was the most vulnerable to the development of acute MI, regardless of the weight category of patients; the back wall was involved in the pathological process both in individuals with overweight and in patients with obesity; the apical segment in the largest number of cases was only affected in people with obesity.

\section{Conflicts of Interest}

The authors declare no conflicts of interest.

\section{References}

1. Bastien M, Poirier P, Lemieux I, et al. Overview of epidemiology and contribution of obesity to cardiovascular disease. Prog Cardiovasc Dis. 2014;56(4):369-81.

2. World Health Organization. Obesity and overweight. 2015.

3. Berrington de Gonzalez A, Hartge P, Cerhan JR, et al. Body-mass index and mortality among 1.46 million white adults. N Engl J Med. 2010;363(23):2211-19.

4. Chumakova GA, Pokutnev AP, Veselovskaya NG. Features of myocardial infarction in patients with obesity. Russ J Cardiol. 2017;4(144):75-80.

5. Grzywocz P, Mizia-Stec K, Wybraniec M, et al. Adipokines and endothelial dysfunction in acute myocardial infarction and the risk of recurrent cardiovascular events. J Cardiovasc Med. 2015;16(1):37-44.

6. Kadakia MB, Fox CS, Scirica BM, et al. Central obesity and cardiovascular outcomes in patients with acute coronary syndrome: observations from the MERLIN-TIMI 36 trial. Heart. 2011;97(21):1782-87.

7. Carmienke S, Freitag MH, Pischon T, et al. General and abdominal obesity parameters and their combination in relation to mortality: a systematic review and meta-regression analysis. Eur J Clin Nutr. 2013;67(6):573-85.

8. Flegal KM, Kit BK, Orpana H, et al. Association of all-cause mortality with overweight and obesity using standard body mass index categories: a systematic review and meta-analysis. JAMA. 2013;309(1):71-82.

9. Veselovskaya NG, Chumakova GA, Kozarenko AA, et al. Adipokines as modifiable risk factors of cardiovascular disease. Russ J Cardiol. 2010;6:88-93. 
10. Aronson D, Nassar M, Goldberg T, et al. The impact of body mass index on clinical outcomes after acute myocardial infarction. Int J Cardiol. 2010;145(3):476-80.

11. Herrmann J, Gersh BJ, Goldfinger JZ, et al. Body mass index and acute and long-term outcomes after acute myocardial infarction (from the harmonizing outcomes with revascularization and stents in acute myocardial infarction trial). Am J Cardiol. 2014;114(1):9-16.

12. Edwards S, Bijlani S, Fairley H, et al. Frequency and prevalence of obesity and related comorbidities in West Texas. Proc (Bayl Univ Med Cent). 2020;33(1):1-4.

13. Khautieva FM, Starodubova AB, Kislyak OA. Features of the course of myocardial infarction in women with overweight and obesity in a city hospital. Russian National Congress of Cardiology. 2009:378.

14. Gupta A, Wang Y, Spertus JA, et al. Trends in acute myocardial infarction in young patients and differences by sex and race, 2001 to 2010. J Am Coll Cardiol. 2014;64(4):337-45.

15. Doughty M, Mehta R, Bruckman D, et al. Acute myocardial infarction in the young- The University of Michigan experience. Am Heart J. 2002;143(1):56-62.

16. UK Prospective Diabetes Study Group. Tight blood pressure control and risk of macrovascular and microvascular complications in type 2 diabetes: UKPDS 38. BMJ. 1998;317:703-13.

17. Obrezan AG, Bitsadze RM. The structure of cardiovascular diseases in patients with type 2 diabetes, diabetic cardiomyopathy as a special condition of the myocardium. International Endocrinological Journal. 2010;28(1):18-22.

18. Dedov II, Shestakova MV. Diabetes mellitus and arterial hypertension. Moscow: Medical Information Agency. 2006:344.

19. Roytberg GE. Metabolic syndrome. 1st ed. Moscow: MEDpress-inform; 2007.

20. Piepoli MF, Hoes AW, Agewall S. et al. 2016 European Guidelines on cardiovascular disease prevention in clinical practice. Eur Heart J. 2016;37(29): 2315-81.

21. Bucholz EM, Rathore SS, Reid KJ, et al. Body mass index and mortality in acute myocardial infarction patients. Am J Med. 2012;125(8):796-803.

22. Csige I, Ujvárosy D, Szabó Z, et al. The impact of obesity on the cardiovascular system. J Diabetes Res. 2018;2018:1-12.

23. Chumakova GA, Veselovskaya NG. Methods of visceral obesity assessment in clinical practice. Russian J Cardiol. 2016;4(1):89-96.

24. Dedov II, Melnichenko GA, Shestakova MV, et al. Morbid obesity treatment in adults. Obesity and metabolism. 2018;15(1):53-70. 